\title{
THE USE OF THE LANGUAGE LABORATORY IN INTERMEDIATE AND ADVANCED CLASSES
}

\author{
by Rebecca M. Valette Boston College
}

The presence of a language laboratory in a school or college has become so commonplace that we now express surprise if we hear of a new school which fails to plan for such an installation. Pictures of students with headsets and a serious expression on their faces are no longer prominently featured in brochures and college catalogs. We have, in fact, become very blase about the laboratory. Too blase, I am afraid. Hardware has become more sophisticated and service more dependable. Teachers and administrators are gradually becoming aware of the administrative organization and daily routine essential to the proper functioning of the equipment. Today it is imperative that we focus our attention on what really goes on in the laboratory. What role does the laboratory play in the learning process? How can learning be enhanced through a more creative use of available equipment?

The officers of NALLD have recognized the need for a new orientation in our attitudes by requesting our adoption of the term "Machine Aided Learning Laboratory." The word "laboratory" describes a controlled environment. The emphasis, however, falls on "learning" and the "machines" are important only inasmuch as they "aid" the learning process. The implication of this term "Machine Aided Learning Laboratory" for us as laboratory directors is obvious. We have spent years designing ideal laboratories, effective scheduling techniques, and new systems for classifying tapes. We have been lobbying for more standardized production on the part of publishers. We have spent endless hours discussing the practical advantages and drawbacks of various installations. It is now time that we raise our sights, that we place the machine and the routine in their proper perspective, and that we give the bulk of our attention to what is-or what should be-taking place in our laboratories: Learning.

If we look back a decade or so historically, we would clearly see that the widespread proliferation of laboratories was closely linked to a specific theory of language learning. Once the acquisition of a second language was equated with the formation of new linguistic habits, then it became evident that new techniques of instruction were needed to attain these objectives. If the student required a great deal of speaking practice with native models, then the language laboratory facilities were

Paper presented at the Fourth Annual Meeting of the National Association of Language Laboratory Directors, March 25, 1968, Houston, Texas. 
ideal. The lab would permit intensive individual work and also allow for control both by the teacher (from the console) and by the student himself (through audio-active headsets and, in some schools, through recording equipment). In the laboratory, dialogs could be overlearned and structure drills could be presented for assimilation. The laboratory would not get tired. The laboratory could be used as an indefatigable drillmaster. More important, it was claimed that all children would learn to speak a foreign language.

Today, however, we must sheepishly admit that all children who spent countless hours in our language laboratories have not learned to speak a second language. Some are pretty good at vocalizing: they rattle off dialogs and breeze through elementary structure drills; but they do not really speak another language. Gradually, language teachers are accepting the existence of the two levels of language postulated by Wilga Rivers in THE PSYCHOLOGIST AND THE FOREIGN LANGUAGE TEACHER: the mechanical level and the understanding level. ${ }^{1}$ The language laboratory was developing the mechanical level, but many audio-lingual programs failed to emphasize the understanding level. Students in school were not tiny children learning their first language with endless repetition and correction: they were thinking human beings who wanted to use a second language for real communication (not just directed dialog) and wanted to know what they were saying and why one form was correct whereas another was not.

Pattern drills can teach you forms such as: If lightning strikes a tree, we say that the tree was struck by lightning. If a car strikes a pedestrian then the pedestrian was struck by a car. If polio strikes a child, however, the child was stricken by polio. But the tree was not stricken by lightning, nor was the pedestrian stricken by a car.

Awareness of meaning, recognition of correctness, and the acquisition of habits are all components in the learning of a language. We must wrench ourselves out of the stimulus-response straight-jacket and accept a more balanced view of language learning. We must provide students with accurate models, but we must also give them some leeway to make mistakes and to learn from those mistakes. We must allow for creative intellectual activity in addition to the intensive exercise of memorization and drill.

Let us now turn to the Machine Aided Learning Laboratory-in its most rudimentary form: the conventional school laboratory-and look at some of the ways in which it can contribute to a more effective foreign language program. We shall limit our remarks to the intermediate and advanced levels, for these are the levels which are most 
frequently neglected. Some of these suggestions will, of course, be adaptable to beginning courses.

At present, the skill which has been most carefully developed in the laboratory has been the speaking skill. One major argument for the installation of a laboratory was that each student would be provided with the opportunity to respond continuously during a half-hour period rather than only two or three times. Wide varieties of structural drills were developed to elicit from the student the range of structures and phrases common to the language being taught. However, most of these drills are of the stimulus-response variety, either the two-phase listenand-repeat drill or of the four-phase stimulus-response-confirmation-repeat drill. What I would like to suggest is the wider use of dialog exercises and anticipation drills. Neither are new and both have been used for many years by NATO instructors in Europe. The dialog exercise is a role-play drill. Once the student has memorized a dialog between two persons the tape instructs him to take one of the roles. During the first round, speaker $A$ is on tape and pauses are left for speaker $B$ 's responses which will be furnished by the student. The pauses are relatively brief so that the tempo of a normal conversation is maintained. Then the roles are reversed. The instruction on the tape says "begin" and the student immediately furnishes speaker A's first line. Students are encouraged to work with this tape until they can play their role fluently. With intermediate classes using dialogs that are too long to be memorized, students are permitted to bring their texts into the laboratory; the exercise becomes one of reading aloud with fluid delivery.

Reading aloud is also the key to the anticipation drill. Before entering the laboratory, the student is handed a text with which he is unfamiliar. The text is divided into breath groups by means of slash marks. The exercise proceeds as follows: The instructor on the tapes says "read". In the subsequent pause the student reads aloud the material up to the first slash mark. Then the native voice on the tape reads the same material. For advanced students, a two-phase drill is maintained: this means, that upon hearing the confirmation of his sentence, the student reads the next phrase or sentence. If needed, however, this drill can be expanded into a four-phase drill: the voice on the tape says "read"; during the first pause, the student reads the first sentence; then the voice on the tape reads the sentence; during the second pause the student repeats the sentence he has just heard, rectifying any mistakes he may have made. The voice on the tape again says "read", and so forth. Although at the elementary level, we want the students to hear sentences before either speaking them or reading them. But with the more advanced students, we would like to feel confident that they can read a paragraph aloud so as to be understood by a native speaker. The antici- 
pation drill provides an excellent means for achieving this latter goal.

Although speaking practice in the laboratory is important, it is only practice. It is contrived. Speech as communication cannot, at the present time, be exercised in the laboratory, because speech is spontaneous expression and calls for the interplay between two or more people.

The new and little-explored frontier in language laboratory materials lies in the direction of the listening skill. As Simon Belasco pointed out in two recent articles in the Modern Language Journal, the development of listening comprehension has been sadly neglected in our curriculum. ${ }^{2}$ Intermediate students should be introduced to all types of speech. At the intermediate level contrived materials are appropriate. Known vocabulary and structures are recombined into a variety of dialogs and expository selections. Students hear this material spoken by different speakers with slightly different accents. Male and female speakers, children and elderly persons can be used in making the recording. The material is recorded not only at a slow and distinct conversational speed, but also at a more normal tempo and then in a rapid speech version. Students are only expected to produce the standard speech at near-conversational speed. But, if the second language is to become a true and effective tool of communication, each student must be able to understand the language under a variety of conditions. When in the foreign country the student may ask for directions in impeccable Spanish, but unless he can understand the colloquial and slurred response of the person to whom he addressed his query, the mere ability to speak the language is of little practical use.

General comprehension of these different varieties of contrived speech can be checked through questions (which can be presented before the tape is played or after), map drawing, pictures, and other testing techniques. In fact, once the taped materials are developed, the matter of checking comprehension becomes relatively simple.

More advanced students can work in controlled materials: these are recordings of actual speech samples of native speakers. Most tape libraries have several types of raw materials on hand: interviews with famous people, lectures, newscasts, sound tracks of movies, and the like. But all too frequently this tape library collects dust in one room while students in more advanced classes are not improving their listening comprehension skills. One effective way of utilizing the resources of the tape library is that proposed by Simon Belasco: several sentences or a snatch of conversation is dubbed on student tapes or cartridges. The

2"Nucleation and the Audio-lingual Approach" $M L J$, XLIX (Dec. 1965), 482-491; "The Plateau; or the Case for Comprehension: the 'concept' Approach, HLJ, LI (Feb. 1967), 82-88. 
students come to the laboratory and take them down a transcription of the recording. In class, individual students put the sentences on the board. Rarely does one student have the entire transcription correct: different students have understood different sections of the text and gradually the entire transcription emerges. A mimeographed copy of the transcription is then distributed and the students return to the laboratory to play back the tape a few more times, with the printed version in front of them. When they can understand the entire transcription without consulting the text, then they are ready to begin work on the next tape.

The use of the transcription can also be varied. For instance, if students seem to be concentrating too much on individual words and sounds, a change of pace may be warranted. One variation is to have students write a resume of the material. Another is to provide a list of printed questions which the students are to answer.

The language laboratory can provide an exciting supplement to literature classes. For years teachers have used recordings of literary works in the classroom. These recordings could be available in the laboratory so that students preparing Act I of Moliere's Bourgeois Gentilbomme, for example, could listen to the tape while reading the text. The versatility of tape, however, can permit much more creative assignments, depending, of course, on the content of the tape library. The most accessible area is poetry. As tape libraries grow, so do the number of "collections", usually poetry collections. Why not splice three different renditions of the same ode or sonnet together on a single student tape? After the student has studied the poem in class with the instructor, he is sent to the laboratory to listen to the new tape. His assignment might be to evaluate the three readings and point out how each reader gives a different interpretation to the poem or, if the contrary be the case, how three different readings bring out various subtle distinctions but all point to a similar broad interpretation. The same type of tapes can be prepared for dramatic scenes, for frequently tape libraries have various versions (or partial versions) of well known plays in the second language. The divorce between professors of literature and the laboratory has been unfortunate, and the heretofore wasted potential of the tape library must now be taped.

My final suggestion for a more creative utilization of the laboratory as a machine-aided learning center was inspired by the March 1, 1968 College and University' Bulletin of the American Association of Higher Education. ${ }^{3}$ I hope that we will be trying out this idea at Boston College next fall, and perhaps many of your schools will be doing the same.

${ }^{3}$ Vol. 20, no. 10 
Let me explain. Last year Bard College experimented with a system by which English professors corrected Freshman English themes on tape. Instead of writing his comments, the teacher dictated his corrections onto tape and returned the paper and the dictaphone belt to the student. Since the grade was given at the end of the commentary, the students listened to the entire tape. The procedure did not save on correction time, but within the same ten to fifteen minutes the instructor had previously spent reading a paper and scribbling some remarks, he now gave a much more extensive personal evaluation of both content and form. Let me quote the final paragraph of this article:

"Most machines save time and destroy personal and intellectual contact between human beings. In this study the machines did not save time, but by providing four to eight times as much information, they made the correction of student work a more meaningful, personal, and intellectual experience, relating the student, the paper, and the instructor in a much more significant way." 4

The one problem that such a system of correction poses for an English department (that is, the large investment in dictaphone equipment) is nonexistent in language departments where the laboratory uses tape or cartridge decks. In correcting literature papers, the teachers can record their comments and corrections in the foreign language, thus introducing extra practice in listening comprehension. In advanced composition courses, the teacher can quickly explain errors, give examples of correct constructions and make specific references, if necessary, to a grammar text. The student would hand in a corrected copy of his composition for the following class meeting.

The use of recording equipment to correct written themes and compositions in intermediate and advanced language classes has, to my knowledge, not been tried. If some of you do carry out or have carried out experiments in this area, I would appreciate your dropping me a line about the results you are achieving and the problems you encounter.

Much creative work remains to be done if our laboratories are to make a more effective contribution to the education process. The new emphasis must be placed on what is happening in the laboratory, not how well the equipment is functioning. We must concentrate on giving present installations a wider role to play in language learning and spend less time dreaming of new technical advances. Of course, the equipment must work. Of course, certain routines are necessary to the proper functioning of the laboratory. But let us now turn to the "software" and focus our attention on teacher and student. Let us concentrate our efforts on truly transforming our electronic installations into Machine Aided Learning Laboratories.

'Iibid, P. 3 